\title{
Physicochemical and textural characteristics and volatile compounds of semihard goat cheese as affected by starter cultures
}

\author{
Rong Jia, ${ }^{1}$ Fuxin Zhang, ${ }^{1}$ Yuxuan Song, ${ }^{2}$ Yuting Lou, ${ }^{1}$ Aiqing Zhao, ${ }^{1}$ Yufang Liu, ${ }^{1}$ Haishuai Peng, ${ }^{1}$ \\ Yuanyuan Hui, ${ }^{1}$ Rong Ren, ${ }^{1}$ and Bini Wang ${ }^{1 *}$ \\ ${ }^{1}$ College of Food Engineering and Nutritional Science, Shaanxi Normal University, Xi'an 710119, China \\ ${ }^{2}$ College of Animal Science and Technology, Northwest A\&F University, Yangling 712100, China
}

\begin{abstract}
Today, cheese is valued because of its high nutritional value and unique characteristics. Improving the texture and flavor of cheese by selecting suitable starter cultures is an important way to promote the development of cheese industry. The effect of starter cultures on the physicochemical and textural properties and volatile compounds during the ripening of semihard goat cheese were investigated in this work. Different starter cultures - mesophilic (M) and thermophilic starters (T), Lactobacillus plantarum ssp. plantarum ATCC 14917 (Lp), a mix of the M and T starters (M1), and mix of the M, T, and Lp starters (M2) - were used in the production of the goat cheeses. Volatile compounds were determined by a solid-phase microextraction/gas chromatography-mass spectrometric (SPME/GC-MS) method. The results showed that the moisture content of cheeses produced with the 5 kinds of starter cultures decreased after maturation, whereas ash content increased. The $\mathrm{pH}$ values of goat cheeses decreased first and then increased during maturity, and the $\mathrm{pH}$ value of M2 cheese was the lowest among the cheeses. The hardness and chewiness of the cheeses increased with increasing maturity, whereas cohesiveness, springiness, and resilience showed the opposite tendency. The 60-dold cheese made with Lp had the highest chewiness, cohesiveness, springiness, and resilience, whereas the 60-d-old cheese made with M2 had the highest hardness. A total of 53 volatile components were identified by SPME/GC-MS, and carboxylic acids, alcohols, ketones, and esters were the 4 major contributors to the characteristic flavors of the cheeses. Volatile components and their contents differed greatly among the produced cheeses. The M2 cheese contained the highest relative content of the main volatile compounds (90.10\%), especially butanoic acid and acetoin. Through a compre-
\end{abstract}

Received May 11, 2020.

Accepted August 8, 2020

*Corresponding author: biniwang@snnu.edu.cn hensive comparison of the results, we concluded that M2 cheese had a dense texture and milky flavor, and M2 is a potential starter culture candidate for the production of goat cheese.

Key words: goat cheese, starter culture, physicochemical and textural characteristic, volatile compound

\section{INTRODUCTION}

Cheesemaking dates back approximately 8,000 years to the Mediterranean coast of southern Turkey but has developed into one of the most advanced food biotechnology applications today (Gobbetti et al., 2015). There are more than 2,500 varieties of cheese around the world. Most cheeses still rely on a combination of 4 ingredients - milk, rennet, microorganisms, and salt - and are processed through several common steps. A variety of fresh cheese curds have largely similar flavors and aromas. However, the physical and chemical properties of cheese change significantly during ripening, along with the production of characteristic flavor compounds (McSweeney and Sousa, 2000). The biochemical changes that occur during cheese ripening can be divided into primary metabolic changes, such as glycolysis, lipolysis, and proteolysis, followed by secondary biochemical changes, such as the metabolism of fatty acids and amino acids, which play a vital role in the production of secondary metabolites, including the amounts of compounds required for flavor formation (Hill and Ross, 1998; McSweeney, 2004). The flavor characteristics of cheese are affected by various flavor compounds, such as carboxylic acids, sulfur compounds, ketones, aldehydes, and alcohols (Seitz, 1990; Urbach, 1993). Among them, organic acids, as important flavor compounds, play an indispensable role in the quality of cheese; they are formed by carbohydrate catabolism and butterfat hydrolysis, normal metabolic processes in ruminants, bacterial growth, or the addition of starter cultures during cheese-making (González de Llano et al., 1996; Akalin et al., 2002; Izco et al., 2002; Murtaza et al., 2012). 
Maturation in cheese is a slow process, which is not completely predictable or controllable (Sihufe et al., 2010). Choosing a suitable starter culture is one of the ways to improve cheese texture and flavor and thus improve cheese characteristics and reduce production costs. Atasoy et al. (2008) found that an increasing number of cheeses were made with pasteurized milk, which necessitated the use of starter culture to ensure acidification and appropriate texture and sensory characteristics. Lactic acid bacteria are usually used as starter cultures in cheese processing. They can produce acid at a certain rate during cheesemaking, which creates favorable conditions for curdling, promotes the discharge of whey, and inhibits the growth of pathogenic bacteria and spoilage microorganisms in cheese. During cheese maturation, lactic acid bacteria can also gradually decompose proteins into peptides, peptones, amino acids, and so on, forming the unique textures and flavors of cheese (El Soda et al., 2000; Pappa and Sotirakoglou, 2008). Commonly used lactic acid bacteria as starter cultures include Lactobacillus, Streptococcus, and Lactococcus (Liu, 2017; Shangpliang et al., 2018; Ren, 2019). In general, Lactococcus lactis ssp. cremoris and Lactococcus lactis ssp. lactis are most widely used in the production of Cheddar cheese (Michel and Martley, 2001). They have strong acid-producing capacity and are beneficial to protein decomposition and autolysis, which are important in the production of cheese (Kenny et al., 2006). Streptococcus thermophilus and Lactobacillus bulgaricus are often used in combination in the production of yogurt products and Mozzarella, Swiss, and Cheddar cheeses (Fox et al., 2004). One of the important functions of this mixture is that it can metabolize galactose and has strong acid resistance, which can reduce the $\mathrm{pH}$ value of fermented milk to $<4$. Lactobacillus plantarum is a probiotic that is widely present in nature. Using probiotics as an auxiliary starter can improve the flavor, texture, and taste of cheese through protein degradation and polysaccharide production (Zhang et al., 2015; Duan et al., 2019). Based on this, the aim of this study was to evaluate the characteristics of goat cheese with different starter cultures including probiotics, with a view to identifying a suitable starter culture for the goat cheeses with a tight texture and milky flavor.

\section{MATERIALS AND METHODS}

\section{Starter Preparation}

The commercial freeze-dried mesophilic and thermophilic starters used in this work were direct-injection starter powders. The mesophilic starter R-704 (M) was from Chr. Hansen (Horsholm, Denmark) and consisted of Lactococcus lactis ssp. cremoris and Lactococcus lactis ssp. lactis. The thermophilic starter YO-MIX495 (T) was from Danisco DuPont (Dangé-Saint-Romain, France) and consisted of Lactobacillus delbrueckii ssp. bulgaricus and Streptococcus thermophilus. Each starter powder was inoculated into sterilized, reconstituted skim milk, incubated at $42^{\circ} \mathrm{C}$ to develop, and was then maintained at 0 to $5^{\circ} \mathrm{C}$ before cheesemaking. Lactobacillus plantarum ssp. plantarum ATCC 14917 (Lp) was stored at $-40^{\circ} \mathrm{C}$, thawed at room temperature, activated and revived for $24 \mathrm{~h}$, diluted, centrifuged, and then mixed with physiological saline before use. Mixed starter 1 (M1) was a mixture of $\mathrm{M}$ and $\mathrm{T}$ at a ratio of 1:1 (wt/wt). Mixed starter 2 (M2) was a mixture of $\mathrm{M}$, $\mathrm{T}$, and $\mathrm{Lp}$ at a 1:1:1 ratio (wt/wt/wt). Cheese samples produced using the above starter cultures were denoted MC, TC, LC, M1C, and M2C, for the starters M, T, $\mathrm{Lp}, \mathrm{M} 1$, and M2, respectively.

\section{Cheese Processing}

Five batches of goat cheeses were produced according to Ren (2010). Ten kilograms of fresh goat milk (purchased from local farmers) was used for each trial. Goat milk was pasteurized at $63^{\circ} \mathrm{C}$ for $30 \mathrm{~min}$ in a cheese trough (GL-10 experimental cheese trough; Shanghai Sunyitech. Co., Ltd., Shanghai, China) and combined with $2 \%$ (wt/wt) activated starter at $32^{\circ} \mathrm{C}$. After the fermentation of goat milk for $40 \mathrm{~min}, 0.4 \mathrm{~g}$ of foodgrade calcium chloride dissolved in $5 \mathrm{~mL}$ of distilled water was added. According to chymosin activity, a calculated amount of chymosin (1:100,000 strength, calf rennet enzyme; Zhengzhou Universe Food Ingredient Limited Company, Henan, China; CAS No. 9001-98-3) was added, and the curds were cut into $1-\mathrm{cm}^{3}$ cubes after $40 \mathrm{~min}$. The temperature was raised to $42^{\circ} \mathrm{C}$ at a rate of $1^{\circ} \mathrm{C} / \mathrm{min}$ while stirring. Whey was drained off, and the curd was collected and weighed. Then, $2.5 \%$ (wt/wt) salt (purchased in a supermarket) was added to the obtained curd mass, which was placed in a cheese mold. The cheese was pressed at $30 \mathrm{~g} / \mathrm{cm}^{2}$ for $6 \mathrm{~h}$ at room temperature and then matured in an incubator at $11.5^{\circ} \mathrm{C}$ with $70 \%$ relative humidity (NL18-20 Intelligent Biochemical Incubator; Ningbo Jiangnan Instrument Factory, Zhejiang, China). After being incubated for $7 \mathrm{~d}$, the cheese was removed and divided into 12 fanshaped pieces, vacuum-sealed, and allowed to mature for up to $60 \mathrm{~d}$ in the incubator at $11.5^{\circ} \mathrm{C}$ and $70 \%$ relative humidity.

\section{Physicochemical Characteristic Determination}

The cheese moisture content (\%) was measured by heating to a constant weight at $105 \pm 2^{\circ} \mathrm{C}$, and ash con- 
tent $(\% \mathrm{DM})$ was determined by the dry ash method at $550^{\circ} \mathrm{C}$ (AOAC official method 935.42; AOAC International, 2000). The moisture and ash contents were determined in triplicate at 1 and $60 \mathrm{~d}$. For $\mathrm{pH}$ measurement, grated cheese samples $(10 \mathrm{~g})$ mixed with $40^{\circ} \mathrm{C}$ distilled water were homogenized at $6,000 \mathrm{rpm}$ for 1 min, transferred to 100-mL volumetric flasks, cooled, diluted, and filtered, and the $\mathrm{pH}$ value of the dispersion was measured in triplicate using a $\mathrm{pH}$ meter (Five Easy Plus pH meter, Mettler-Toledo AG, Schwerzenbach, Switzerland) at 1, 7, 15, 30, 45, and $60 \mathrm{~d}$.

\section{Texture Profile}

In this study, the texture of the 5 types of cheese was evaluated at $1,7,15,45$, and $60 \mathrm{~d}$ of ripening using the TA.XT. Plus Texture Analyzer (Stable Micro Systems Ltd., Godalming, UK). The fan-shaped cheese samples were taken from the incubator, the skin was removed, and the samples were equilibrated to room temperature. Each sample was then cut into 4 thinner fan shapes with a thickness of $1 \mathrm{~cm}$ before analysis. The texture profile analysis (TPA) double compressiondecompression cycle test was performed with a stainless steel cylindrical probe (diameter $36 \mathrm{~mm}$ ) at a speed of $1 \mathrm{~mm} / \mathrm{s}$ with an interval of $3 \mathrm{~s}$. The TPA indicators recorded were hardness, cohesiveness, springiness, chewiness, and resilience.

\section{Volatile Compounds}

Volatile compounds of 60 -d-old cheese samples were extracted by automated solid-phase microextraction (SPME) with a CTC CombiPal autosampler (CTC Analytics, Zwingen, Switzerland) and analyzed by TRACE DSQ gas GC-MS (Thermo Fisher Scientific, Waltham, MA). Five grams of ground cheese sample was weighed into a headspace bottle, and vials were placed on an autosampler tray and subjected to SPME. After bottles had been sealed and equilibrated at $40^{\circ} \mathrm{C}$ for $15 \mathrm{~min}$, the SPME head was inserted, and the headspace was adsorbed for $10 \mathrm{~min}$. A 50/30 $\mu \mathrm{m}$ Stable Flex divinylbenzene/carboxen/polydimethylsiloxane (DVB/CAR/PDMS)-coated fiber (Supelco, Bellefonte, PA) was used for headspace extraction. Desorption into the $\mathrm{GC}$ injection port was performed at $250^{\circ} \mathrm{C}$ for 3 min in splitless mode. Chromatographic separation was carried out in a DB-17MS capillary column $(60 \mathrm{~m} \times$ $0.25 \mathrm{~mm} \times 0.25 \mu \mathrm{m}$; Agilent Technologies, Santa Clara, CA) with high-purity helium as the carrier gas at a flow rate of $1.0 \mathrm{~mL} / \mathrm{min}$. The following temperature program was used: $3 \mathrm{~min}$ at $40^{\circ} \mathrm{C}$, increased at $4^{\circ} \mathrm{C} / \mathrm{min}$ to $120^{\circ} \mathrm{C}$, increased at $6^{\circ} \mathrm{C} / \mathrm{min}$ to $240^{\circ} \mathrm{C}$, and then held for $12 \mathrm{~min}$ at $240^{\circ} \mathrm{C}$. Electron impact ionization with an electron energy of $70 \mathrm{eV}$, a scan range of 35 to $500 \mathrm{amu}$, and an ion source temperature of $230^{\circ} \mathrm{C}$ were used. The volatile compounds were qualitatively screened based on the unknown compounds detected and matched to the NIST 14 mass spectral library (https://chemdata .nist.gov/); only substances with a similarity greater than $85 \%$ were reported. The relative percentage of the compounds was calculated by peak area normalization.

\section{Statistical Analysis}

Statistical treatment of data was performed using SPSS software (version 17.0, SPSS Inc., Chicago, IL). Data were subjected to one-way ANOVA; ANOVA with cheese age as the main effect was performed on analytical variables, and comparison of means was carried out by using Tukey's test $(P=0.05)$. Figures were plotted using Origin (v 8.5) software (Origin Lab Corporation, Northampton, MA). Principal component analysis (PCA) with maximum variation rotation was carried out on volatile compounds.

\section{RESULTS AND DISCUSSION}

\section{Physicochemical Characteristics}

The moisture content of cheese not only affects the cheese yield but also plays an essential role in cheese quality. The moisture content of cheeses made with the selected starter cultures ranged between 37 and 50\% (Figure 1), which classified them as semihard cheeses (Tie, 2015). The moisture content of all cheeses decreased after $60 \mathrm{~d}$ of maturation. Generally, a decrease in moisture content of the cheese is caused by evaporation of free water (Pappa et al., 2006), which was also confirmed by the water droplets observed in vacuum bags in this work. After cheeses had matured for 60 $\mathrm{d}$, the moisture contents of $\mathrm{MC}, \mathrm{LC}$, and $\mathrm{M} 2 \mathrm{C}$ were significantly higher than those of TC and M1C $(P<$ 0.05 ). This difference might be due to proteolysis in $\mathrm{MC}, \mathrm{LC}$, and $\mathrm{M} 2 \mathrm{C}$ during cheese maturation, which led to the production of new amino and carboxyl groups with higher water-holding capacity, resulting in higher moisture content in mature cheeses (Lawrence et al., 1987).

Compared with the 5 cheese samples at $1 \mathrm{~d}$ of maturity, the ash contents at $60 \mathrm{~d}$ of maturity increased by 13.13 to $39.20 \%$ (Figure 1). This might be due to the synergistic effect of the pre-acidification of raw milk and the addition of calcium chloride (Liu, 2012), which caused more inorganic salts to be embedded in the curd structure. In addition, the reduction in moisture content of cheeses after maturation would increase their relative DM and salt contents (Khosrowshahi et al., 2006). The 
60-d-old LC had a higher ash content than the other cheese samples $(P<0.05)$, which could be attributed to the retention of calcium chloride and sodium chloride in the cheese curds by Lp. The ash contents of LC were the highest both at 1 and $60 \mathrm{~d}$ of maturity. This could be attributed to their softer granular curds produced by Lp than other groups, which led to more salt added. Therefore, the highest ash contents were found in LC. However, the composition of inorganic salt ions and their contents in cheese need further study.

Among several factors that affect the physicochemical properties of cheese, $\mathrm{pH}$ value is critical because it directly influences the stability of casein micelles and milk minerals (Pastorino et al., 2003). Figure 2 indicates that the $\mathrm{pH}$ values of $\mathrm{LC}$ and $\mathrm{M} 1 \mathrm{C}$ were significantly higher than those of MC, TC, and M2C $(P<$ $0.05)$ during maturation. These differences in $\mathrm{pH}$ could be caused by the different composition of the lactic acid bacteria in starters and their interaction (Walstra et al., 2005; Özer and Kesenkaş, 2019). The increase in $\mathrm{pH}$ value of mature cheese might also be due to the decomposition of lactic acid and the formation of basic compounds (Upreti et al., 2006; Piras et al., 2013; Özer and Kesenkaş, 2019). In addition, M2C showed the lowest $\mathrm{pH}$ value, which might be because Lp could further enhance the acid-producing ability of the strains in $\mathrm{M}$ and $\mathrm{T}$. This result was similar to that reported by Liu (2018), who found that addition of probiotics to a commercial starter culture could lower the $\mathrm{pH}$ of Cheddar cheese.

\section{Texture Profile}

Textural properties of goat cheeses with different starter cultures are shown in Table 1 . We found that the hardness of the cheese samples at $1 \mathrm{~d}$ of maturity was negatively correlated with moisture content, which could be due to the composition of lactic acid bacteria in starter cultures. The 1-d-old TC had the highest hardness and the lowest moisture content, which could be attributed to the rapid rate of acid production by $\mathrm{T}$. This was consistent with the finding that changes in moisture content had a significant effect on the texture of fresh cheese reported by Gunasekaran and Mehmet

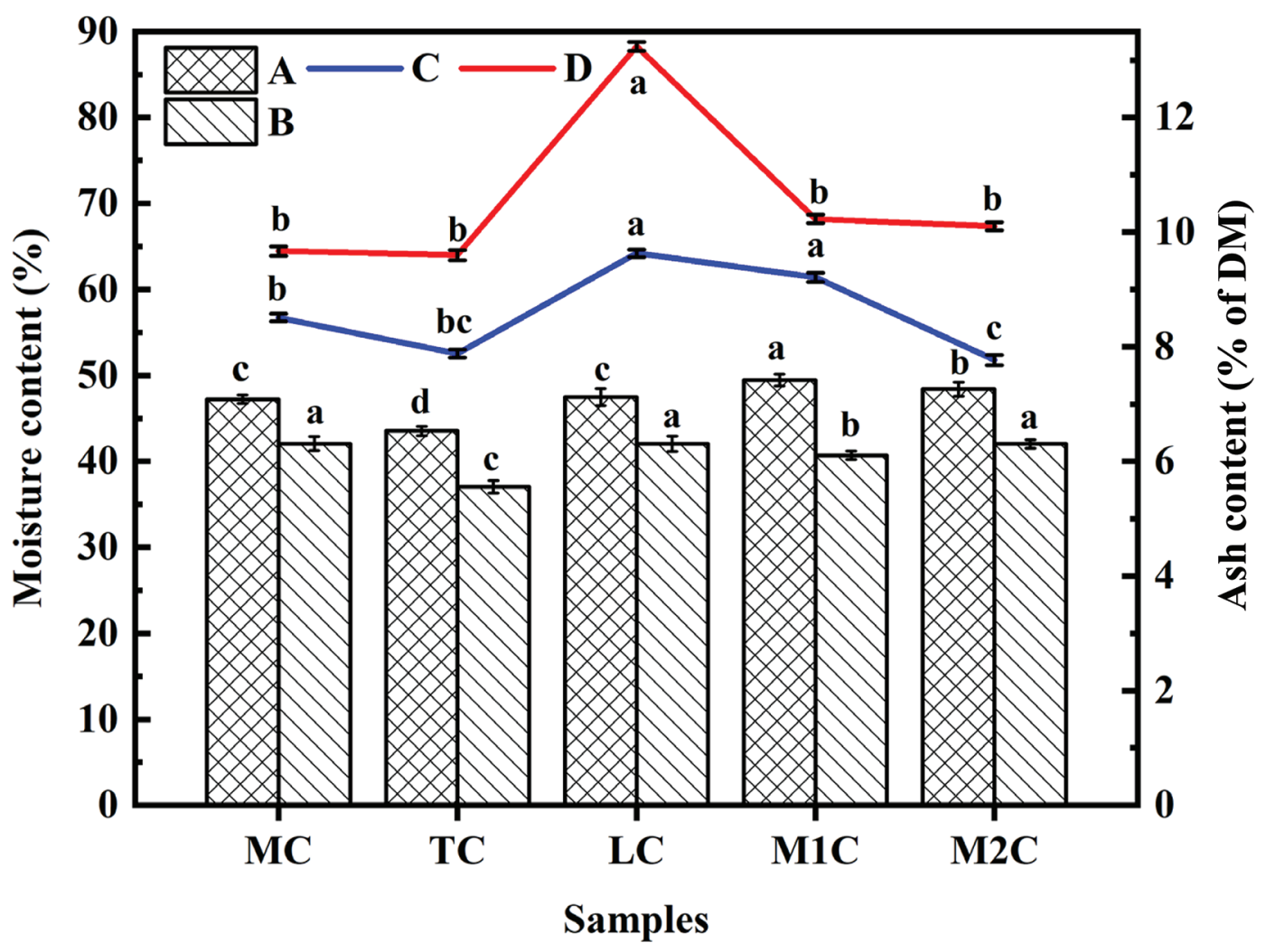

Figure 1. Effect of starter cultures on moisture and ash contents in cheese. Moisture contents of cheese samples at $1 \mathrm{~d}(\mathrm{~A})$ and $60 \mathrm{~d}(\mathrm{~B})$ and ash contents at maturity of $1 \mathrm{~d}(\mathrm{C})$ and $60 \mathrm{~d}(\mathrm{D})$ in $\mathrm{MC}$ (cheese made with mesophilic starter, M), TC (cheese made with thermophilic starter, T), LC (cheese made with Lactobacillus plantarum ssp. plantarum ATCC 14917; Lp), M1C (cheese made with a 1:1 mix of M and T starters), and M2C (cheese made with a 1:1:1 mix of M, T, and Lp starters). Mean values at the same maturity with different letters (a-d) are significantly different $(P<0.05)$. Error bars represent standard deviations. 


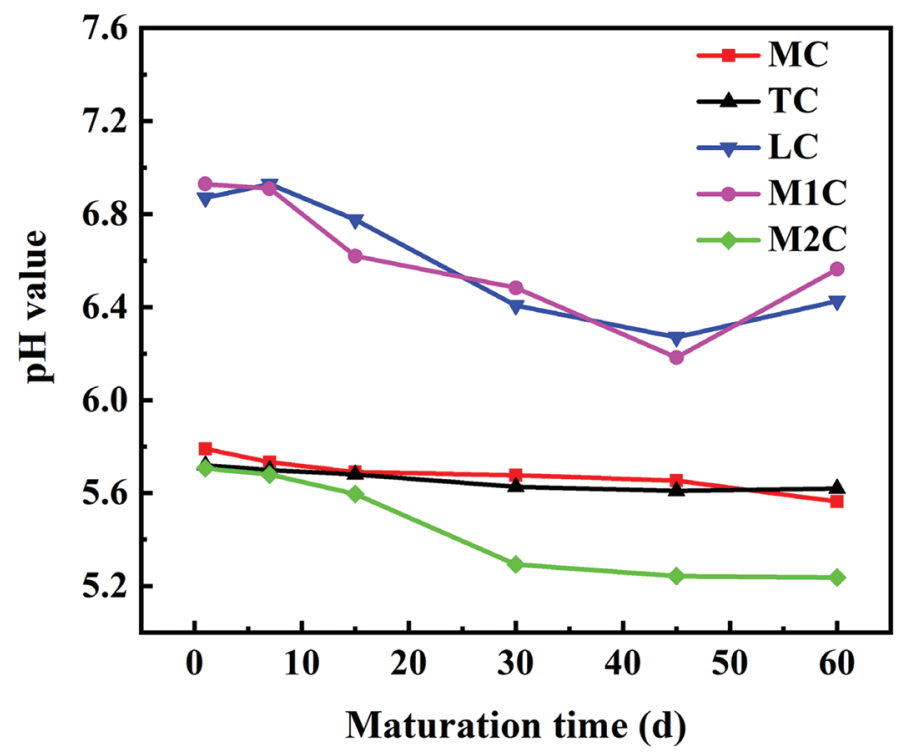

Figure 2. Effect of the starter cultures on $\mathrm{pH}$ values in cheese. $\mathrm{pH}$ values of cheese samples at $1,7,15,30,45$, and $60 \mathrm{~d}$ in MC (cheese made with mesophilic starter, M), TC (cheese made with thermophilic starter, T), LC (cheese made with Lactobacillus plantarum ssp. plantarum ATCC 14917; Lp), M1C (cheese made with a 1:1 mix of M and $\mathrm{T}$ starters), and M2C (cheese made with a 1:1:1 mix of M, T, and Lp starters).
(2002). The hardness of cheese samples showed an overall upward trend with increasing maturity, although the hardness of LC reached a maximum at $7 \mathrm{~d}$ and then decreased. The increase in hardness during maturation of goat cheese was similar to that reported for semihard ewe milk (Juan et al., 2007), Manchego-type (Pavia et al., 1999), and Swiss-type (Rohm and Lederer, 1992) cheeses. In this study, the hardness of 60 -d-old $\mathrm{M} 2 \mathrm{C}$ was the highest but did not significantly differ from that of MC, LC, and M1C $(P>0.05)$. Li (2011) reported that the cheese made with a mesophilic starter had large internal voids and loose texture, which confirmed our finding of low hardness in MC. The addition of Lp to M2 might have gradually homogenized the inner space of the cheese and tightened the texture as cheese ripened, resulting in the highest hardness being found in $\mathrm{M} 2 \mathrm{C}$.

Chewiness demonstrated a similar trend to hardness, and was in accordance with the study of Zheng et al. (2012) that chewiness was a secondary characteristic positively correlated with hardness. At $60 \mathrm{~d}$ of maturation, LC had the highest chewiness but it did not differ significantly from that of $\mathrm{TC}, \mathrm{M} 1 \mathrm{C}$, and $\mathrm{M} 2 \mathrm{C}(P>$ $0.05)$.

Table 1. Textural properties of goat cheese samples with different starter cultures (means $\pm \mathrm{SD}, \mathrm{n}=4$ )

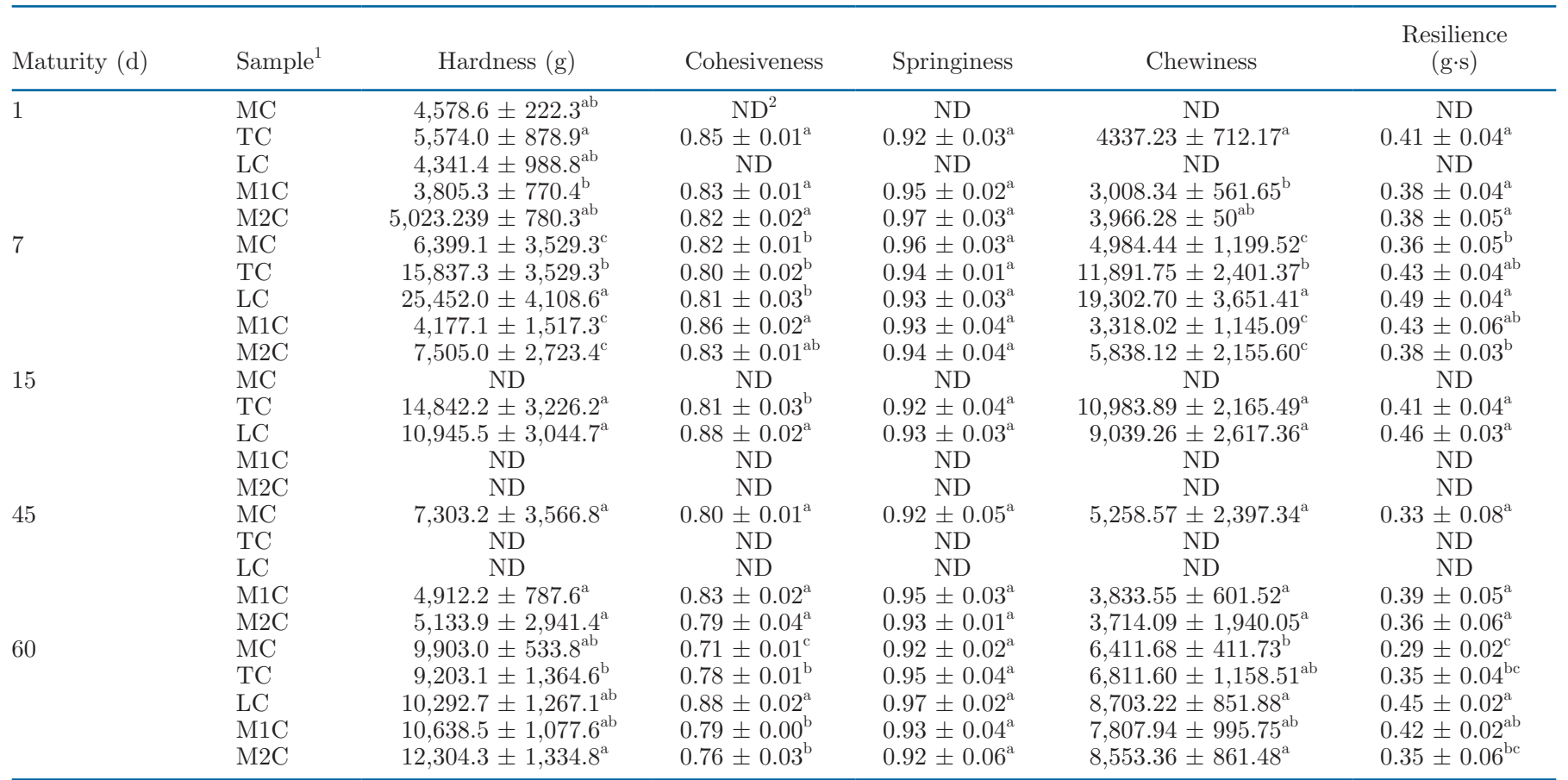

\footnotetext{
${ }^{\mathrm{a}-\mathrm{c}}$ Means in the same column of the same timepoint with different superscripts are significantly different $(P<0.05)$.

${ }^{1} \mathrm{MC}=$ cheese made with mesophilic starter $(\mathrm{M}) ; \mathrm{TC}=$ cheese made with thermophilic starter $(\mathrm{T})$; LC = cheese made with Lactobacillus plantarum ssp. plantarum ATCC $14917(\mathrm{Lp}) ; \mathrm{M} 1 \mathrm{C}=$ cheese made with a 1:1 mix of M and T starters; and M2C= cheese made with a 1:1:1 mix of $\mathrm{M}, \mathrm{T}$, and Lp starters.

${ }^{2} \mathrm{ND}=$ not detected.
} 
As maturation time progressed, the cohesiveness of all cheese samples, except LC, decreased slightly. Protein and fat are continuously broken down during the ripening process. Casein is first hydrolyzed into long-chain peptides, which subsequently decompose into short-chain peptides. Some of the casein eventually decompose into amino acids and volatile substances. After being dispersed into small fat globules, the large fat globules are further broken down into ketones, aldehydes, and lactones, which decompose into volatile substances and free fatty acids (Collins et al., 2003; Aminifar et al., 2010). Hydrolysis of the components in cheese caused viscosity to gradually increase during the ripening process, and the cohesiveness gradually decreased. The cohesiveness of $60-\mathrm{d}$-old LC was significantly higher than that of $\mathrm{MC}, \mathrm{TC}, \mathrm{M} 1 \mathrm{C}$, and $\mathrm{M} 2 \mathrm{C}(P$ $<0.05$ ); the differences among cheeses might be related to the production of extracellular polysaccharides by lactic acid bacteria in starter cultures (Adhikari et al., 2003).

The springiness of $\mathrm{MC}, \mathrm{M} 1 \mathrm{C}$, and $\mathrm{M} 2 \mathrm{C}$ and the resilience of MC, TC, LC, and M2C all decreased slightly after cheese maturation. Resilience is a manifestation of cheese springiness. Lobato-Calleros et al. (2008) reported that fresh cheese proteins are highly cross-linked in a 3-dimensional network and showed high resistance to deformation, meaning the cheese was more elastic. The difference in springiness among our cheese samples at $60 \mathrm{~d}$ was not significant $(P>0.05)$, whereas the resilience of LC was significantly higher than that of MC, TC, and M2C $(P<0.05)$. The results showed that $\mathrm{M} 2 \mathrm{C}$ had a denser texture than LC, whereas LC was more viscoelastic and had higher resistance to deformation. The overall changes in hardness, chewiness, cohesiveness, springiness, and resilience were consistent with results reported by O'Mahony et al. (2005).

\section{Volatile Compounds}

A total of 53 volatile compounds were detected by SPME/GC-MS in the 5 cheese samples matured for 60 d; these included acids, alcohols, aldehydes, ketones, esters, alkenes, alkanes, and other volatile compounds. The volatile compounds reported here have also been found in Australian white-brined cheeses (Horwood et al., 1981), low-fat feta-type cheese (Katsiari et al., 2002), feta cheese (Kondyli et al., 2012), and Teleme cheese (Massouras et al., 2006; Pappa et al., 2013). Their relative contents in cheeses prepared using various starter cultures differed after $60 \mathrm{~d}$ of maturation (Figure 3). Among these volatile compounds, carboxylic acids, alcohols, ketones, and esters were the most abundant and were the 4 major contributors to cheese flavor. The total of their relative contents was highest $(90.10 \%)$ in $\mathrm{M} 2 \mathrm{C}$ and lowest $(47.90 \%)$ in TC.

Carboxylic acids constituted from $9.78 \%$ (TC) to $46.82 \%$ (M2C) of the total detected volatile compounds present in the 5 cheeses (Figure 3). This wide range might be caused by the composition of different lactic acid bacteria, which could promote the production of carboxylic acids in cheese due to their lipolytic activity (Ávila et al., 2007; Randazzo et al., 2008). Of these acids, acetic acid, butanoic acid, and octanoic acid had the highest relative contents of total carboxylic acids in M2C, with only heptanoic acid not being detected. Heptanoic acid was only detected in LC, whereas hexanoic acid was the principal carboxylic acid in MC, TC, and M1C; hexanoic acid is mostly found in Seda cheese and blue cheese with a slightly rancid cheese-like smell (Niu, 2010). Butanoic acid was the predominant volatile component in $\mathrm{M} 2 \mathrm{C}$, accounting for $23.38 \%$ of the total detected compounds. This was consistent with previously published results (Woo et al., 1984; Woo and Lindsay, 1984), which reported that butanoic acid could contribute to the typical flavors of Limburger, Provolone, Romano, and Camembert cheeses. Octanoic acid has a weak fruit acid smell and a light sour taste (Curioni and Bosset, 2002; Luis Barron et al., 2005), and $n$-decanoic acid, at a low concentration, results in a milky flavor (Hu et al., 2011), which was only detected in $\mathrm{M} 2 \mathrm{C}$. These results were in accordance with a previous report (Poveda and Cabezas, 2006) that identified the source of the typical flavor of goat cheese as being related to free fatty acids, especially free hexanoic acid, octanoic acid, and $n$-decanoic acid.

Alcohols dominated in MC, TC, LC, and M1C, with the relative contents of the total volatile compounds exceeding $23 \%$; alcohols were present at a very low level $(2.44 \%)$ in M2C (Figure 3). They have frequently been reported as precursors of other aromatic compounds in many cheeses (Carbonell et al., 2002; Bontinis et al., 2012; Kondyli et al., 2012). Ethanol was detected in all 5 cheeses but was the only alcohol in $\mathrm{M} 2 \mathrm{C}$, at a relatively low level (2.44\%). 1-Butanol has floral, aromatic, fruity, and sweet properties (Curioni and Bosset, 2002; Barron et al., 2005), and 2-methyl-1-butanol and 3-methyl-1-butanol were both detected at the highest relative concentrations in TC. In particular, 3-methyl1-butanol is considered responsible for the faint odor of bovine Mozzarella and it imparts a pleasant aroma to fresh cheese.

Ketones were the most predominant volatile compounds in LC and M2C, with relative contents of 29.13 and $35.27 \%$, respectively. Acetoin had the highest relative content among ketones in all cheese samples; it is considered to contribute to the characteristic milky fla- 
vor of domestic cheeses (Yi, 2008). Its relative content in $\mathrm{M} 2 \mathrm{C}(33.11 \%)$ was much higher than that in other cheeses $(<16.56 \%)$, which could be caused by the synergistic effects of Lp, M, and T producing more acetoin in cheese samples.

The relative content of esters was highest (15.77\%) in $\mathrm{MC}$ and lowest in $\mathrm{M} 2 \mathrm{C}$ (5.57\%). In all detected ester constituents, butanolic acid ethyl ester, hexanoic acid ethyl ester, and octanoic acid ethyl ester were detected in all cheese samples; butanolic acid ethyl ester had the highest relative contents. These 3 esters all have a sweet, fruity, and ice-cream flavor. In particular, buta- noic acid ethyl ester has been identified as one of the most powerful flavoring agents for Cheddar, Emmental, creamy Gorgonzola, Grana Padano, and Pecorino cheeses, and hexanoic acid ethyl ester appears to be significant in the aromas of aged Cheddar, natural Gorgonzola, Grana Padano, and Pecorino cheeses, with a flavor of pineapple and banana. In addition, octanoic acid ethyl ester plays an important role in forming the aroma of Floede Guia cheese, contributing a coconutlike flavor (Curioni and Bosset, 2002). However, esters have negative as well as positive effects on cheese flavor, depending on the concentration of esters and the type

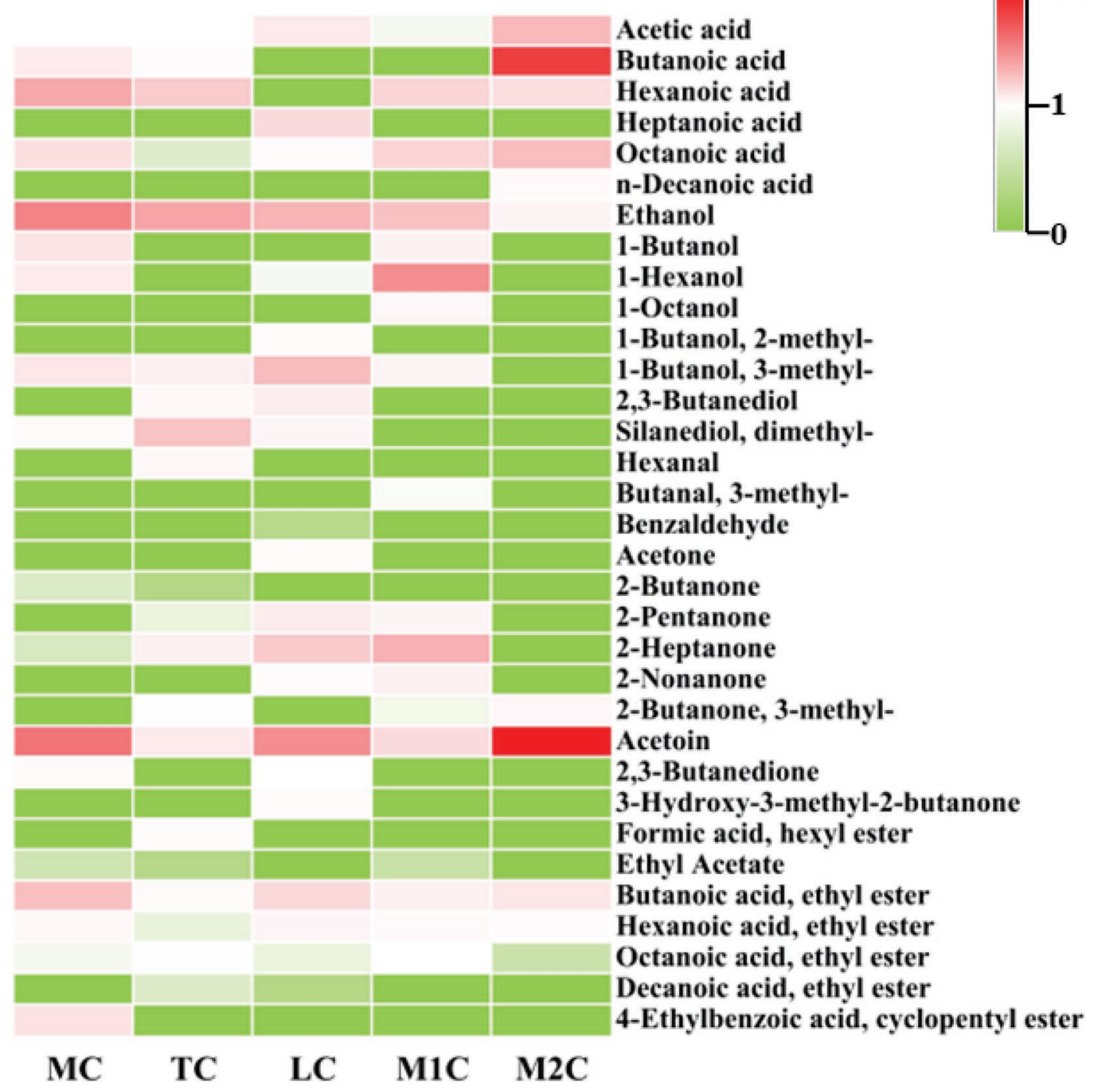

Figure 3. Hierarchical nonclustering analysis of differential aroma compounds in five 60-d-old cheese samples: MC (cheese made with mesophilic starter, M), TC (cheese made with thermophilic starter, T), LC (cheese made with Lactobacillus plantarum ssp. plantarum ATCC 14917; $\mathrm{Lp}), \mathrm{M} 1 \mathrm{C}$ (cheese made with a 1:1 mix of $\mathrm{M}$ and T starters), and M2C (cheese made with a 1:1:1 mix of M, T, and Lp starters). The color box for each compound indicates the abundance of the compound: red = higher abundance and green = zero abundance. The scale in the color bar is the original abundance of the compound. 
of cheese (Liu et al., 2004). Although the 3 esters were present in $\mathrm{M} 2 \mathrm{C}$ at relatively minor levels, M2C had a pleasant flavor.

In general, butanoic acid and acetoin, which contribute to the typical flavor of cheese, were the most predominant volatile compounds in $\mathrm{M} 2 \mathrm{C}$, accounting for $56.49 \%$ of the total detected compounds. Thus, M2C had flavors characteristic of cheese.

\section{PCA}

Principal components analysis was used to correlate volatile compounds and distinguish cheeses that had matured for $60 \mathrm{~d}$. Figure 4 demonstrates the loading plots of volatile compounds in the plane defined by the principal components (PC) 1, 2, and 3. Figure 5 shows the loading plots of the factor scores for each cheese sample, which is the distribution of cheeses in the plane defined by the PC.

Principal component 1 explained $32.30 \%$ of the variance, which was negatively correlated with the content of carboxylic acids in each group except for heptanoic acid. The correlation values were acetic acid, -0.325 ; butanoic acid, -0.673 ; hexanoic acid, -0.654 ; heptanoic acid, 0.911; octanoic acid, -0.719 ; and n-decanoic acid, -0.613 . The content of carboxylic acids in $\mathrm{M} 2 \mathrm{C}$ was the highest, which resulted in the volatile compounds of the $\mathrm{M} 2 \mathrm{C}$ cheese being located on the left side of Figure 5. Principal component 2, which explained $26.33 \%$ of the variance, was positively related to esters (other than hexanoic acid ethyl ester), several alcohols, and aldehydes and was negatively correlated with carboxylic acids other than hexanoic acid. For M2C, these volatile compounds were located on the left of Figure 5 , and the remaining groups of cheese were located on the right. Principal component 3 accounted for $21.66 \%$ of the variance and was positively related to carboxylic acids other than hexanoic acid. The volatile compounds of TC were located in the lower part of Figure 5, with those of $\mathrm{MC}, \mathrm{LC}, \mathrm{M} 1 \mathrm{C}$, and $\mathrm{M} 2 \mathrm{C}$ in the upper part. Considering the proportions of $\mathrm{PC} 1, \mathrm{PC} 2$, and $\mathrm{PC} 3$, we can conclude that M2 had the optimal impact on

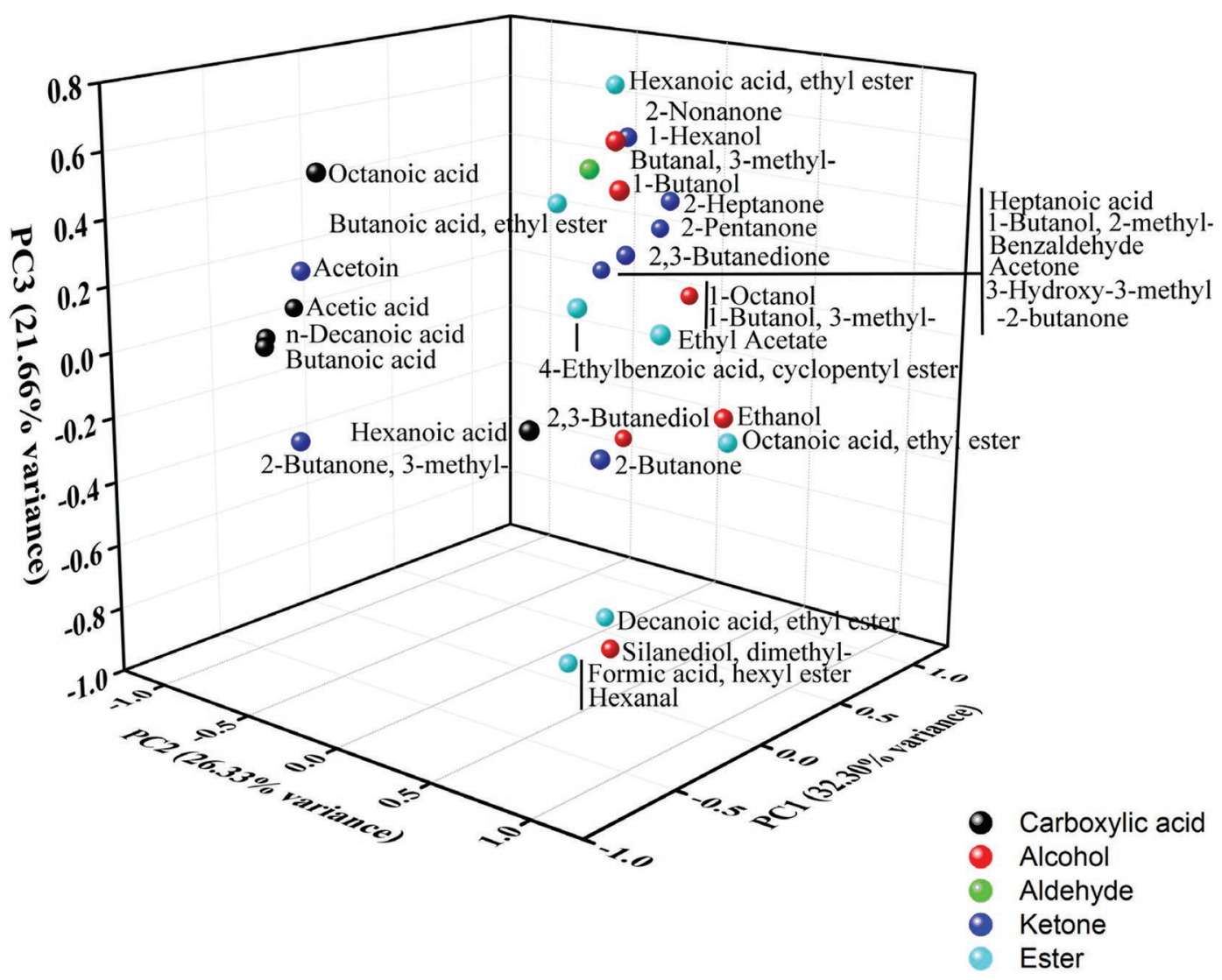

Figure 4. Principal component (PC) analysis plot showing the distribution of volatile compounds of 60-d-old cheese in MC (cheese made with mesophilic starter, M), TC (cheese made with thermophilic starter, T), LC (cheese made with Lactobacillus plantarum ssp. plantarum ATCC 14917; Lp), M1C (cheese made with a 1:1 mix of M and T starters), and M2C (cheese made with a 1:1:1 mix of M, T, and Lp starters). 


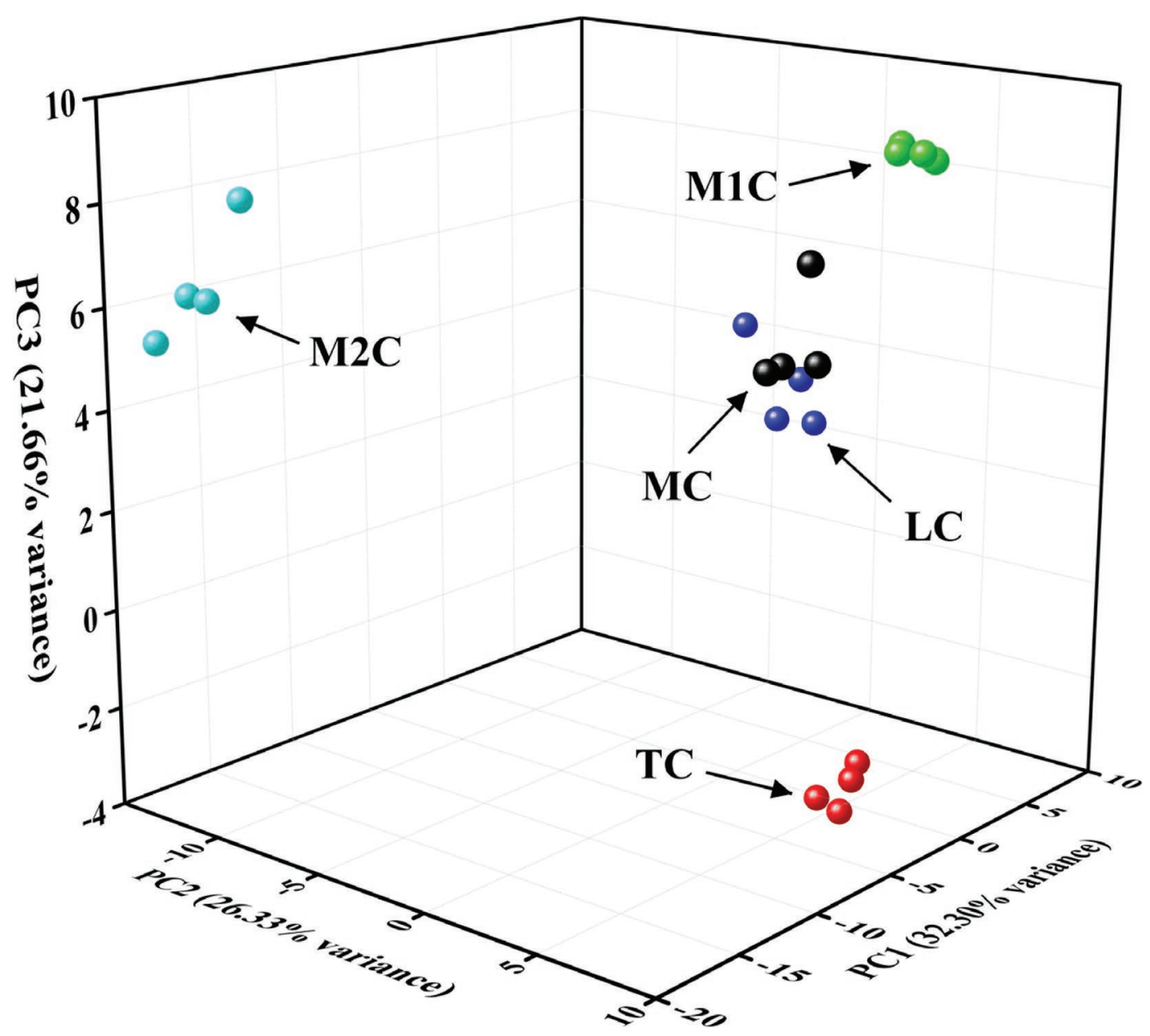

Figure 5. Distribution of 60-d-old cheeses in the plane defined by principal components (PC)1, 2, and 3 of principal component analysis in Figure 3. Goat cheeses were MC (cheese made with mesophilic starter, M), TC (cheese made with thermophilic starter, T), LC (cheese made with Lactobacillus plantarum ssp. plantarum ATCC 14917; Lp), M1C (cheese made with a 1:1 mix of M and T starters), and M2C (cheese made with a 1:1:1 mix of $\mathrm{M}, \mathrm{T}$, and Lp starters).

cheese made from goat milk compared with the other test starters; the addition of Lp in starter cultures improved the characteristic milky flavor of mature cheese.

\section{CONCLUSIONS}

The starter cultures used in this study had a limited effect on the physicochemical properties of goat cheese but a pronounced effect on texture and volatile components. After $60 \mathrm{~d}$ of maturation, LC was more viscoelastic and had a higher resistance to deformation than $\mathrm{MC}$, TC, M1C, and M2C, whereas M2C had the densest texture. The relative content of volatile compounds peaked in 60-d-old M2C and the cheese had a pleasant milky flavor. Therefore, we concluded that the M2 starter, which was composed of M, T, and Lp at a ratio of 1:1:1 (wt/wt/wt), is a potential candidate for producing compact (dense) and milky goat cheese. The characteristic flavor synthesis process and the potential health benefits of goat cheese prepared using different starter cultures should be further investigated.

\section{ACKNOWLEDGMENTS}

This research was funded by the Key Industry Innovation Chain Project of Key R\&D Program in Shaanxi Province (No. 2019ZDLNY06-06 and 2020ZDLNY02-08, Shaanxi, China), the Science and Technology Program of Xi'an City (No. 20NYYF0014 and 20NYYF0018, Shaanxi, China), the Agricultural Science and Technology Innovation Project of Department of Agriculture of Shaanxi Province (No. NYK-2019-XA-007, Shaanxi, China), and the Fundamental Research Funds for the Central Universities (No. GK202003084, Shaanxi, China). The authors have not stated any conflicts of interest. 


\section{REFERENCES}

Adhikari, K., H. Heymann, and H. E. Huff. 2003. Textural characteristics of lowfat, fullfat and smoked cheeses: Sensory and instrumental approaches. Food Qual. Prefer. 14:211-218. https://doi.org/10 $.1016 /$ S0950-3293(02)00067-8.

Akalin, A. S., S. Gonc, and Y. Akbas. 2002. Variation in organic acids content during ripening of pickled white cheese. J. Dairy Sci. 85:1670-1676. https://doi.org/10.3168/jds.S0022-0302(02)74239 -2 .

Aminifar, M., M. Hamedi, Z. Emam-Djomeh, and A. Mehdinia. 2010. Microstructural compositional and textural properties during ripening of Lighvan cheese, a traditional raw sheep cheese. J. Texture Stud. 41:579-593. https://doi.org/10.1111/j.1745-4603.2010.00244 .x.

AOAC International. 2000. Official Methods of Analysis.15th ed. AOAC International, Arlington, VA.

Atasoy, A. F., A. Yetişmeyen, H. Türkoğlu, and B. Özer. 2008. Effects of heat treatment and starter culture on the properties of traditional Urfa cheeses (a white-brined Turkish cheese) produced from bovine milk. Food Control 19:278-285. https://doi.org/10.1016/j foodcont.2007.04.004.

Ávila, M., J. Calzada, S. Garde, and M. Nuñez. 2007. Effect of a bacteriocin-producing Lactococcus lactis strain and high-pressure treatment on the esterase activity and free fatty acids in Hispánico cheese. Int. Dairy J. 17:1415-1423. https://doi.org/10.1016/j .idairyj.2007.04.004.

Barron, L. Jr., Y. Redondo, M. Aramburu, F. J. Pérez-Elortondo, M. Albisu, A. I. Nájera, and M. de Renobales. 2005. Variations in volatile compounds and flavour in Idiazabal cheese manufactured from ewe's milk in farmhouse and factory. J. Sci. Food Agric. 85:1660-1671. https://doi.org/10.1002/jsfa.2175.

Bontinis, T. G., H. Mallatou, E. C. Pappa, Th. Massouras, and E. Alichanidis. 2012. Study of proteolysis, lipolysis, and volatile profile of a traditional Greek goat cheese (Xinotyri) during ripening. Small Rumin. Res. 105:193-201. https://doi.org/10.1016/j .smallrumres.2012.01.003.

Carbonell, M., M. Nunez, and E. Fernandez-Garcia. 2002. Evolution of the volatile components of ewe raw milk La Serena cheese during ripening. Correlation with flavour characteristics. Dairy Sci. Technol. 82:683-698. https://doi.org/10.1051/lait:2002042.

Collins, Y. F., P. L. H. Mcsweeney, and M. G. Wilkinson. 2003. Lipolysis and free fatty acid catabolism in cheese: A review of current knowledge. Int. Dairy J. 13:841-866. https://doi.org/10.1016/ S0958-6946(03)00109-2.

Curioni, P. M. G., and J. O. Bosset. 2002. Key odorants in various cheese types as determined by gas chromatography-olfactometry. Int. Dairy J. 12:959-984. https://doi.org/10.1016/S0958 -6946(02)00124-3.

Duan, C. C., S. Y. Li, Z. J. Zhao, C. Wang, Y. J. Zhao, G. E. Yang, Ch. H. Niu, L. Gao, X. X. Liu, and L. Zhao. 2019. Proteolytic activity of Lactobacillus plantarum strains in cheddar cheese as adjunct cultures. J. Food Prot. 82:2108-2118. https://doi.org/10 .4315/0362-028X.JFP-19-276.

El Soda, M., S. A. Madkor, and P. S. Tong. 2000. Adjunct cultures: Recent developments and potential significance to the cheese industry. J. Dairy Sci. 83:609-619. https://doi.org/10.3168/jds .S0022-0302(00)74920-4.

Fox, P. F., P. L. McSweeney, T. M. Cogan, and T. P. Guinee. 2004. Cheese: Chemistry, Physics and Microbiology: General aspects, vol 1. Elsevier Academic Press, London, UK.

Gobbetti, M., M. De Angelis, R. Di Cagno, L. Mancini, and P. F. Fox. 2015. Pros and cons for using non-starter lactic acid bacteria (NSLAB) as secondary/adjunct starters for cheese ripening. Trends Food Sci. Technol. 45:167-178. https://doi.org/10.1016/j tifs.2015.07.016.

González de Llano, D., A. Rodriguez, and P. Cuesta. 1996. Effect of lactic starter cultures on the organic acid composition of milk and cheese during ripening-analysis by HPLC. J. Appl. Bacteriol. 80:570-576. https://doi.org/10.1111/j.1365-2672.1996.tb03259.x.
Gunasekaran, S., and A. K. Mehmet. 2002. Cheese Rheology and Texture. 1st ed. Taylor and Francis Group, CRC Press, Boca Raton, FL.

Hill, C., and P. Ross. 1998. Genetic modification in food industry. Pages 174-175 in Starter Cultures for the Dairy Industry. Blackie Academic and Professional/Thomson Science, London, UK.

Horwood, J. F., G. T. Llound, and W. Stark. 1981. Some flavour components of Feta cheese. Aust. J. Dairy Technol. 36:34-37.

Hu, S. Q., H. L. Wei, S. S. Guo, L. Li, and Y. Hou. 2011. Flavor evaluation of yak butter in Tsinghai-Tibet Plateau and isolation of microorganisms contributing flavor. Anim. Sci. J. 82:122-126. https://doi.org/10.1111/j.1740-0929.2010.00803.x.

Izco, J. M., M. Tormo, and R. Jimenez-Flores. 2002. Rapid simultaneous determination of organic acids, free amino acids, and lactose in cheese by capillary electrophoresis. J. Dairy Sci. 85:2122-2129. https://doi.org/10.3168/jds.S0022-0302(02)74290-2.

Juan, B., A. J. Trujillo, V. Guamis, M. Buffa, and V. Ferragut. 2007. Rheological, textural and sensory characteristics of high-pressure treated semi-hard ewes' milk cheese. Int. Dairy J. 17:248-254. https://doi.org/10.1016/j.idairyj.2006.02.009.

Katsiari, M. C., L. P. Voutsinas, and E. Kondyli. 2002. Improvement of sensory quality of low-fat Kefalograviera-type cheese with commercial adjunct cultures. Int. Dairy J. 12:757-764. https://doi .org/10.1016/S0958-6946(02)00066-3.

Kenny, O., R. J. Fitzgerald, G. O'Cuinn, T. Beresford, and K. Jordan. 2006. Autolysis of selected Lactobacillus helveticus adjunct strains during Cheddar cheese ripening. Int. Dairy J. 16:797-804. https:/ /doi.org/10.1016/j.idairyj.2005.07.008.

Khosrowshahi, A., A. Madadlou, M. Ebrahim zadeh Mousavi, and Z. Emam-Djomeh. 2006. Monitoring the chemical and textural changes during ripening of Iranian White cheese made with different concentrations of starter. J. Dairy Sci. 89:3318-3325. https:// doi.org/10.3168/jds.S0022-0302(06)72368-2.

Kondyli, E., E. C. Pappa, and A. M. Vlachou. 2012. Effect of package type on the composition and volatile compounds of Feta cheese. Small Rumin. Res. 108:95-101. https://doi.org/10.1016/ j.smallrumres.2012.06.014.

Lawrence, R. C., L. K. Creamer, and J. Gilles. 1987. Texture development during cheese ripening. J. Dairy Sci. 70:1748-1760. https:// doi.org/10.3168/jds.S0022-0302(87)80207-2.

Li, L. 2011. Physical and biochemical changes during ripening of double-protein cheese made from cows and soya milk blends using selection starters. Shengyang Agricultural University, Shengyang, China.

Liu, J. 2012.Technology optimization and application of rennet casein. Tianjin University of Science and Technology, Tianjin, China.

Liu, J. Y. 2017. Study on Preparing Technology of the Lactic Acid Bacteria Direct Vat Set and its Application. Shandong Agricultural University, Taian, China.

Liu, L. 2018. Effect of Probiotics on the Production Mechanism of Cheese Bioactive Peptides and their Structural Characteristics. Northeast Agricultural University, Harbin, China.

Liu, S. Q., R. Holland, and V. L. Crow. 2004. Esters and their biosynthesis in fermented dairy products: A review. Int. Dairy J. 14:923945. https://doi.org/10.1016/j.idairyj.2004.02.010.

Lobato-Calleros, C., A. Sosa-Perez, J. Rodriguez-Tafoya, O. SandovalCastilla, C. Pérez-Alonso, and E. J. Vernon-Carter. 2008. Structural and textural characteristics of reduced-fat cheese-like products made from W-1/O/W-2 emulsions and skim milk. Food Sci. Technol. 41:1847-1856. https://doi.org/10.1016/j.lwt.2008.01.006.

Massouras, T., E. C. Pappa, and H. Mallatou. 2006. Headspace analysis of volatile flavour compounds of Teleme cheese made from sheep and goat milk. Int. J. Dairy Technol. 59:250-256. https:// doi.org/10.1111/j.1471-0307.2006.00268.x.

McSweeney, P. L. H. 2004. Biochemistry of cheese ripening. Int. J. Dairy Technol. 57:127-144. https://doi.org/10.1111/j.1471-0307 .2004.00147.x.

McSweeney, P. L. H., and M. J. Sousa. 2000. Biochemical pathways for the production of flavour compounds in cheeses during ripening: A review. Lait 80:293-324. https://doi.org/10.1051/lait:2000127. 
Michel, V., and F. G. Martley. 2001. Streptococcus thermophilus in Cheddar cheese - Production and fate of galactose. J. Dairy Res. 68:317-325. https://doi.org/10.1017/S0022029901004812.

Murtaza, M. A., S. U. Rehman, F. M. Anjum, N. Huma, O. M. Tarar, and G. Mueen-ud-Din. 2012. Organic acid contents of buffalo milk Cheddar cheese as influenced by accelerated ripening and sodium salt. J. Food Biochem. 36:99-106. https://doi.org/10.1111/j.1745 $-4514.2010 .00517 . x$.

Niu, J. 2010. Research on Yak's Milk Soft Cheese Technology and Flavor Compounds in Ripening Process. Gansu Agricultural University, Lanzhou, China.

O'Mahony, J. A., J. A. Lucey, and P. L. H. Mc Sweeney. 2005. Chymosin-mediated proteolysis, calcium solubilization, and texture development during the ripening of Cheddar cheese. J. Dairy Sci. 88:3101-3114. https://doi.org/10.3168/jds.S0022-0302(05)72992 $-1$.

Özer, E., and H. Kesenkaş. 2019. The effect of using different starter culture combinations on ripening parameters, microbiological and sensory properties of Mihaliç cheese. J. Food Sci. Technol. 56:1202-1211. https://doi.org/10.1007/s13197-019-03583-2.

Pappa, E. C., I. Kandarakis, E. M. Anifantakis, and G. K. Zerfiridis. 2006. Influence of types of milk and culture on the manufacturing practices, composition and sensory characteristics of Teleme cheese during ripening. Food Control 17:570-581. https://doi.org/ 10.1016/j.foodcont.2005.03.004.

Pappa, E. C., T. Massouras, K. Sotirakoglou, and I. Kandarakis. 2013. Formation of volatile compounds in Teleme cheese manufactured with mesophilic and thermophilic dairy starters. Small Rumin. Res. 111:110-119. https://doi.org/10.1016/j.smallrumres.2012.10 .013 .

Pappa, E. C., and K. Sotirakoglou. 2008. Changes of free amino acid content of Teleme cheese made with different types of milk and culture. Food Chem. 111:606-615. https://doi.org/10.1016/j .foodchem.2008.04.027.

Pastorino, A. J., C. L. Hansen, and D. J. McMahon. 2003. Effect of pH on the chemical composition and structure-function relationships of Cheddar cheese. J. Dairy Sci. 86:2751-2760. https://doi.org/10 .3168/jds.S0022-0302(03)73871-5.

Pavia, M., B. Guamis, A. J. Trujillo, M. Capellas, and V. Ferragut. 1999. Changes in microstructural, textural and colour characteristics during ripening of Manchego-type cheese salted by brine vacuum impregnation. Int. Dairy J. 9:91-98. https://doi.org/10 .1016/S0958-6946(99)00027-8.

Piras, C., F. C. Marincola, F. Savorani, S. B. Engelsen, S. Cosentino, S. Viale, and M. B. Pisano. 2013. A NMR metabolomics study of the ripening process of the Fiore Sardo cheese produced with autochthonous adjunct cultures. Food Chem. 141:2137-2147. https:/ /doi.org/10.1016/j.foodchem.2013.04.108.

Poveda, J. M., and L. Cabezas. 2006. Free fatty acid composition of regionally-produced Spanish goat cheese and relationship with sensory characteristics. Food Chem. 95:307-311. https://doi.org/ 10.1016/j.foodchem.2004.12.045.

Randazzo, C. L., I. Pitino, S. de Luca, G. O. Scifò, and C. Caggia. 2008. Effect of wild strains used as starter cultures and adjunct cultures on the volatile compounds of the Pecorino Siciliano cheese. Int. J. Food Microbiol. 122:269-278. https://doi.org/10 .1016/j.ijfoodmicro.2007.12.005.

Ren, J. 2010. The applied technology of different starter cultures in goat cheese. Shaanxi Normal University, Xi'an, China.

Ren, M. 2019. Screening of Lactococcus lactis ssp. lactis with superior fermentation characteristics. Inner Mongolia Agricultural University, Inner Mongolia, China.

Rohm, H., and H. Lederer. 1992. Uniaxial compression of Swiss-Type cheese at different strain rates. Int. Dairy J. 2:331-343. https://doi .org/10.1016/0958-6946(92)90025-H.

Seitz, E. W. 1990. Microbial and enzyme induced flavors in dairy foods. J. Dairy Sci. 73:3664-3691. https://doi.org/10.3168/jds .S0022-0302(90)79070-4.

Shangpliang, H. N., R. Rai, S. Keisam, K. Jeyaram, and J. P. Tamang. 2018. Bacterial community in naturally fermented milk products of Arunachal Pradesh and Sikkim of India analysed by high-throughput amplicon sequencing. Sci. Rep. 8:1532. https:// doi.org/10.1038/s41598-018-19524-6.

Sihufe, G. A., S. E. Zorrilla, M. C. Perotti, I. V. Wolf, C. A. Zalazar, N. G. Sabbag, S. C. Costa, and A. C. Rubiolo. 2010. Acceleration of cheese ripening at elevated temperature. An estimation of the optimal ripening time of a traditional Argentinean hard cheese. Food Chem. 119:101-107. https://doi.org/10.1016/j.foodchem .2009.06.001.

Tie, G. 2015. The effect of process conditions on the quality characteristics of semi-hard cheese. Inner Mongolia Agricultural University, Inner Mongolia, China.

Upreti, P., L. L. Mckay, and L. E. Metzger. 2006. Influence of calcium and phosphorus, lactose, and salt-to-moisture ratio on Cheddar cheese quality: Changes in residual sugars and water-soluble organic acids during ripening. J. Dairy Sci. 89:429-443. https://doi .org/10.3168/jds.S0022-0302(06)72159-2.

Urbach, G. 1993. Relations between cheese flavor and chemical composition. Int. Dairy J. 3:389-422. https://doi.org/10.1016/0958 -6946(93)90025-U.

Walstra, P., J. T. M. Wouters, and T. J. Geurts. 2005. Dairy Science and Technology, (2nd ed.). Taylor and Francis Group, CRC Press, Boca Raton, FL.

Woo, A. H., S. Kollodge, and R. C. Lindsay. 1984. Quantification of major free fatty acids in several cheese varieties. J. Dairy Sci. 67:874-878. https://doi.org/10.3168/jds.S0022-0302(84)81380-6.

Woo, A. H., and R. C. Lindsay. 1984. Concentrations of major free fatty acids and flavour development in Italian cheese varieties. J. Dairy Sci. 67:960-968. https://doi.org/10.3168/jds.S0022 -0302(84)81394-6.

Yi, Y. J. 2008. Research on Flavor of Domestic Cheddar Cheese. Jiangnan University, Wuxi, China.

Zhang, L., X. Li, H. Ren, L. Liu, L. Ma, M. Li, and W. Bi. 2015. Impact of using exopolysaccharides (EPS)-producing strain on qualities of half-fat Cheddar cheese. Int. J. Food Prop. 18:1546-1559. https://doi.org/10.1080/10942912.2014.921198.

Zheng, Y. R., Zh. M. Liu, B. H. Mo, H. Y. Gao, and K. J. Sun. 2012 Effects of microstructure change on the texture of cheddar cheese during ripening. Zhongguo Nong Ye Ke Xue 45:503-508. 